\title{
A prevalência do desvio fonológico em crianças de 4 a 6 anos de escolas públicas municipais de Salvador-BA
}

\author{
Laura Giotto Cavalheiro ${ }^{1}$
}

Cavalheiro LG. A prevalência do desvio fonológico em crianças de 4 a 6 anos de escolas públicas municipais de Salvador-BA [tese]. Santa Maria: Universidade Federal de Santa Maria; 2007.

Este estudo teve por objetivos estimar a prevalência de desvios fonológicos em crianças de 4 a 6 anos que freqüentam escolas públicas municipais de Salvador-BA; verificar se a prevalência de desvios fonológicos varia conforme a idade, o sexo, e a classe socioeconômica; verificar a ocorrência de alterações no inventário fonético, sistema fonológico e os processos fonológicos de maior prevalência apresentados pelas crianças que apresentam desvio fonológico. A amostra foi formada por 2.880 crianças de ambos os sexos, na faixa etária de 4:0 a 6:11, de níveis socioeconômicos baixo, médio e alto. Todos foram submetidos às avaliações fonoaudiológicas e, posteriormente, avaliação fonológica, realizadas a fim de determinar a prevalência do desvio fonológico para diferentes sexos, faixas etárias e níveis socioeconômicos. Para a análise estatística, foram utilizados o Teste Qui-quadrado de Pearson ou Teste Exato de Fisher, com nível de significância de 5\% (p<0,05). A prevalência do desvio fonológico foi de $9,17 \%$ na população estudada. Ao verificar esta prevalência, considerando a variável sexo, foi encontrada $13,33 \%$ para o sexo masculino e $5 \%$ para o feminino. Ao considerar a faixa etária 8,9\% das crianças de 4:0 a 4:11, 9,48\% para as crianças de 5:0 a 5:11 e 9,06\% para as crianças de 6:0 a 6:11. Em relação ao nível sócio-econômico foi verificado que 8,75\% dos sujeitos de nível sócio-econômico baixo apresentam desvio fonológico, 9,69\% do nível médio, e $9,06 \%$ do alto. Das crianças avaliadas, apenas $1,11 \%$ tem inventário fonético incompleto e 1,32\% sistema fonológico incompleto. Os processos fonológicos mais prevalentes são os de estruturação silábica, comparados aos de substituição, sendo que o processo fonológico mais tardiamente eliminado é o de redução de encontro consonantal. Há variação no desempenho relacionado aos processos fonológicos e, também, estatisticamente quando analisados os processos fonológicos em diferentes sexos e níveis socioeconômicos. Conclui-se, dessa forma, que há alta prevalência de desvio fonológico em crianças de 4:0 a 6:11, com variações na manifestação do desvio, considerando sexo e nível socioeconômico, diferentemente do que é observado ao analisar a faixa etária.

Trabalho apresentado à Universidade Federal de Santa Maria - UFSM Santa Maria (RS), Brasil, para obtenção do título de Mestre em Distúrbios da Comunicação Humana, sob orientação da Profa. Dra. Márcia Keske-Soares. Trabalho Premiado com Menção Honrosa no Congresso Brasileiro de Fonoaudiologia em 2008.

(1) Mestre, Professora do Curso de Fonoaudiologia do Centro Universitário Jorge Amado - UNIJORGE, União Metropolitana de Educação e Cultura - UNIME e Faculdade Nobre de Feira de Santana - FAN - Salvador (BA), Brasil.

Endereço para correspondência: Laura Giotto Cavalheiro. Al. Praia de Guaratuba, 1575/11, Stella Mares, Salvador - BA, CEP 41600-270. E-mail: laufono@uol.com.br 